\title{
Effects of Electron Beam Irradiation on Impact Value of Carbon Fiber Reinforced Thermoplastic Polyetheretherketone
}

\author{
Yoshitake Nishi ${ }^{1,2,3}$, Hiroaki Takei ${ }^{1, *}$, Keisuke Iwata $^{2, *}$, Michelle Salvia $^{4}$ and Alain Vautrin ${ }^{3}$ \\ ${ }^{1}$ Graduate School of Metallurgical Engineering, Tokai University, Hiratsuka 259-1292, Japan \\ ${ }^{2}$ Doctoral Graduate School of Science and Engineering, Tokai University, Hiratsuka 259-1292, Japan \\ ${ }^{3}$ Department of Mechanical and Materials Engineering, Ecole Nationale Superieure des Mines de Saint-Etienne, \\ Saint-Étienne Cedex 2 42023, France \\ ${ }^{4}$ Ecole Centrale de Lyon, Ecully Cedex 69134, France
}

Homogeneous low voltage electron beam irradiation (HLEBI) improves the Charpy impact value $\left(a_{\mathrm{uc}}\right)$ of composites sheets of carbon fiber reinforced thermoplastic polyetheretherketone (CFRTP) with $2 \mathrm{~mm}$ thickness, although the irradiated depth estimated is $177 \pm 32 \mu \mathrm{m}$ at their both sides surface. The $a_{\mathrm{uc}}$ values at low fracture probability $\left(P_{\mathrm{f}}\right)$ of 0.13 for CFRTP irradiated at $0.43 \mathrm{MGy}\left(\mathrm{kJg}^{-1}\right)$ is $78 \mathrm{kJm}^{-2}$, which is $56 \%$ higher than that $\left(50 \mathrm{kJm}^{-2}\right)$ for CFRTP before irradiation. Although the lowest impact values $\left(a_{\mathrm{s}}\right)$ estimated by three parameters Weibull equation is zero for CFRTP before irradiation, HLEBI enhances the $a_{\mathrm{s}}$ value. The highest $a_{\mathrm{s}}$ value is more than $55 \mathrm{kJm}^{-2}$ for CFRTP irradiated from 0.43 to $0.65 \mathrm{MGy}$. Thus, HIEBL remarkably enhances the $a_{\mathrm{s}}$ value, as well as the $a_{\mathrm{uc}}$ value at low $P_{\mathrm{f}}$ value. Since HLEBI enhances the Weibull coefficient $(n)$, it also enhances the reproducibility of CFRTP samples. The maximum $n$ value is found at 0.43 MGy of HLEBI dose. The interfacial friction force, as well as the strengthening of both carbon fiber and polyetheretherketone probably contributes the HLEBI effects to enhance the $a_{\mathrm{s}}$ value of CFRTP, as well as enhancement of reproducibility. [doi:10.2320/matertrans.M2009210]

(Received June 19, 2009; Accepted September 25, 2009; Published November 18, 2009)

Keywords: thermoplastic, polyetheretherketone, carbon fiber, electron beam irradiation, impact value

\section{Introduction}

Carbon fiber reinforced polymers [CFRP], which are typical composite materials, and have been applied as light structural materials with high strength. ${ }^{1,2)}$ The further strengthening has been always expected to develop highspeed transports with small energy consumption. Although influences of electron beam (EB) irradiation with high energy on the fracture toughness of carbon cross of carbon fibers in thermo-hardened epoxy resin matrix (thermo-hardened CFRP) have been often reported, ${ }^{3)}$ no one has succeeded the strengthening of CFRP irradiated by electron beam.

On the other hand, the homogeneous low voltage electron beam irradiation (HLEBI) often induces not only the hardening, high wear resistance and sterilization for practical use of polymer, but also the mist resistance. ${ }^{4-6)}$ In addition, the irradiation has improved not only the bending fracture strain of carbon fiber, ${ }^{7,8)}$ but also the deformation resistivity, strength and fracture strain on static tensile test. ${ }^{9)}$ In our recent research, it has succeeded that the EB-irradiation also enhances the fracture stress and fracture strain of static bending test of thermo-hardened CFRP ${ }^{10)}$ Furthermore, the improvement of impact value of thermo-hardened CFRP by EB-irradiation has been also reported to apply to high-speed transports. $^{11)}$

Carbon fiber reinforced thermoplastic polymers (CFRTP), already applied for automobile bumper and IC substrate, can be easily produced with high productivity for mass production at various forming process. However, it is serious problem that high viscosity of thermoplastic polymer with low wetting to carbon fiber induces the low strength of CFRTP. HLEBI often enhances the deformation resistivity (elasticity) of polymer ${ }^{12)}$ and carbon fiber. ${ }^{7-9)}$ In addition,

*Graduate Student, Tokai University

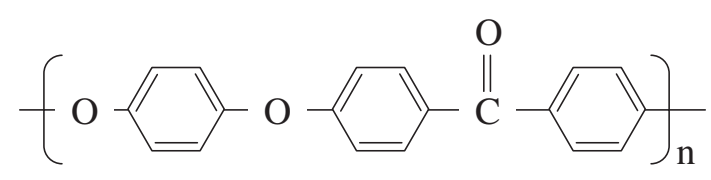

Fig. 1 Rational formula of Polyetheretherketone (PEEK).

it is also possible to enhance the interface strength induced by surface activation, which is generated by charging and dangling bond formation.

Since the interfacial area of carbon fiber with $6 \mu \mathrm{m}$ diameter is extremely large, the enhancement of friction force induces the strength of CFRP. In order to enhance the interfacial friction force, the HLEBI to interface in CFRTP is probably effective. Polyetheretherketone (PEEK), which monomer is mainly constructed with three six-membered rings (see Fig. 1), is one of typical thermoplastic superengineering polymer with high resistance to heat, wear and reaction. ${ }^{13)}$ Thus, it is generally applied to interior and upholster of cabin in airplane and automobile. Therefore, the purpose of the present work is to investigate effects of HLEBI on impact value of CFRTP constructed with polyetheretherketone and carbon fiber.

\section{Experimental Procedure}

\subsection{CFRTP sample preparation}

The CFRTP sample, which volume is $1600 \mathrm{~mm}^{3}$, has been constructed with the bundle of carbon fiber (Diameter $=$ $6 \mu \mathrm{m}, \mathrm{T} 800 \mathrm{HB}$, Toray Industries, Inc.) and thermoplastic polymer (Polyetheretherketone; APTIV 2000-025, Victrex plc) matrix. Volume fractions of carbon fiber and polymer matrix are 52.6 and $47.4 \mathrm{vol} \%$, respectively.

Making composites is performed under $2.0 \mathrm{MPa} \mathrm{Ar}-\mathrm{H}_{2}$ gas atmosphere at $350^{\circ} \mathrm{C}$ for $10 \mathrm{~min}$. 
Since the bundle direction is a longitudinal direction, the high unidirectional strength can be expected. To evaluate the dynamic fracture toughness, the impact tests of the CFRP with and without the irradiation are measured using a standard impact test machine (Shimadzu Corporation No. 51735).

\subsection{Impact test}

In order to evaluate the impact fracture toughness, the Charpy impact values of the CFRTPs with and without HLEBI were measured using a standard impact fracture energy measurement system (Shimadzu Corporation No. 51735) (JIS K 7077). ${ }^{11,14)}$ The CFRTP sample, which sizes are $80 \mathrm{~mm}$ length, $10 \mathrm{~mm}$ width and $2.0 \mathrm{~mm}$ thickness. The impact fracture energy $(E)$ was expressed by the following equation. ${ }^{11,14)}$

$E=W R\left[(\cos \beta-\cos \alpha)-\left(\cos \alpha^{\prime}-\cos \alpha\right)(\alpha+\beta) /\left(\alpha-\alpha^{\prime}\right)\right]$

Here, $E, W, R, \beta, \alpha$ and $\alpha^{\prime}$ were impact fracture energy $(\mathrm{kJ})$, hammer mass $(\mathrm{kg})$, length $(\mathrm{m})$ of hammer weight point from rolling center, start angle before impact, the maximum angle after impact and the maximum angle of the blank test, respectively. The Charpy impact value $\left(a_{\mathrm{uc}}: \mathrm{kJm}^{-2}\right)$ was expressed by the following equation.

$$
a_{\mathrm{uc}}=E /(b t)
$$

Here, $E, b(=10 \pm 0.2 \mathrm{~mm})$ and $t(=2.00 \pm 0.15 \mathrm{~mm})$ were impact fracture energy $(\mathrm{J})$, sample width $(\mathrm{mm})$ and span distance (sample thickness, $\mathrm{mm}$ ), respectively. The distance between supporting points was $40 \mathrm{~mm}$.

\subsection{Condition of EB-irradiation}

Sheet electron beam irradiation with low energy has been homogeneously performed using an electron-curtain processor (Type CB175/15/180L, Energy Science Inc., Woburn, MA). ${ }^{4-12)}$ The specimen is machined from the sheet heat-treated for making composites and is homogeneously irradiated with the electron beam through a titanium thin film window attached to the vacuum chamber, $240 \mathrm{~mm}$ in diameter. Since HLEBI treated after forming interface between carbon fiber and PEEK matrix, improvement of adhesive force can be expected. A tungsten filament in vacuum is used to generate the electron beam at a low energy (acceleration potential, $V: \mathrm{kV}$ ), of $170 \mathrm{kV}$ and irradiating current density $\left(\mathrm{J}: \mathrm{Am}^{-2}\right)$ of $0.089 \mathrm{Am}^{-2}$. Although electron beam generation has been in vacuum, the irradiated sample has been kept under protective nitrogen at atmospheric pressure. The distance between sample and window has been $35 \mathrm{~mm}$. To prevent oxidation, the samples are kept in a protective one atmosphere of nitrogen gas with a residual concentration of oxygen of below $400 \mathrm{ppm}$. The flow rate of the nitrogen gas is $1.5 \mathrm{Ls}^{-1}$ at $0.1 \mathrm{MPa}$ of nitrogen gas pressure. Each irradiation dose $\left(0.043 \mathrm{MGy}\left(\mathrm{kJg}^{-1}\right)\right)$ is applied for only a short time $(0.23 \mathrm{~s})$ to avoid excessive heating of the sample; the temperature of the sample surface remains below $323 \mathrm{~K}$ just after irradiation. The sample in the aluminum plate holder $(0.15 \mathrm{~m} \times 0.15 \mathrm{~m})$ is transported on a conveyor at a speed of $9.56 \mathrm{~m} \cdot \mathrm{min}^{-1}$. The sheet electron beam irradiation has been applied intermittently. Repeated irradiations to both side surfaces of samples are used to increase the total dose of irradiation. The interval between the end of one period of irradiation and the start of the next operation is $30 \mathrm{~s}$. When the irradiation current $(I: \mathrm{mA})$, the conveyor speed $\left(S: \mathrm{m} \cdot \mathrm{min}^{-1}\right)$ and number of irradiations $(N)$ are determined, the irradiated dose ( $D$ : MGy) is expressed by a following equation. ${ }^{15)}$

$$
D=0.216(I / S) N
$$

The irradiation dose has been controlled by the integrated irradiation time in each of the samples. Here, irradiation dose has been corrected by using FWT nylon dosimeter of RCD radiometer film (FWT-60-00: Far West Technology, Inc. 330-D South Kellogg Goleta, California 93117, USA) with irradiation reader (FWT-92D: Far West Technology, Inc. 330-D South Kellogg Goleta, California 93117, USA). The dose is $0.0432 \mathrm{MGy}$ at each irradiation.

\subsection{Evaluation of dangling bonds}

To obtain more precise information on atomic-scale structural changes in the CFRTP, the density of the dangling bonds was obtained using an electron spin resonance spectrometer (ESR, JES-FA200, Nippon Denshi Ltd. Tokyo). ${ }^{9)}$ The microwave frequency range used in the ESR analysis was the X-band at $9.45 \pm 0.05 \mathrm{GHz}$ with a field modulation of $100 \mathrm{kHz}$. The microwave power was $1 \mathrm{~mW}$. The magnetic field was varied from 318.7 to $328.7 \mathrm{mT}$. The spin density was calculated using a $\mathrm{Mn}^{2+}$ standard sample. Only ESR spectra, instead of spin densities, were given.

\section{Results}

\subsection{Effects of HLEBI on impact value}

Evaluating the probability of fracture $\left(P_{\mathrm{f}}\right)$ is a convenient method of quantitative analyzing experiment values relating to fracture. $P_{\mathrm{f}}$ is expressed by the following equation, which is a generalized form of the median rank method: ${ }^{16)}$

$$
P_{\mathrm{f}}=(i-0.3) /\left(N_{\mathrm{s}}+0.4\right)
$$

where $N_{\mathrm{s}}$ and $i$ are the total number of samples $\left(N_{s}=11\right)$ and the order of fracture of each sample, respectively. Here, the order of fracture is the aligned number of fractured samples from low to high impact value. When the $i$ values are 2, 6, and 10 , the $P_{\mathrm{f}}$ values are $0.13,0.50$, and 0.85 , respectively.

Figure 2 shows changes in impact value $\left(a_{\mathrm{uc}}\right)$ of CFRTP against $P_{\mathrm{f}}$ value at each dose of HLEBI.

Remarkable effects of HLEBI on $a_{\mathrm{uc}}$ value of CFRTP have been obtained at low $P_{\mathrm{f}}$ value of less than 0.2 . The direct irradiation of more than $0.12 \mathrm{MGy}$ remarkably enhances the $a_{\mathrm{uc}}$ value of the CFRTP at low $P_{\mathrm{f}}$ value of less than 0.2 .

Figure 3 shows changes in $a_{\mathrm{uc}}$ value of CFRTP against dose of HLEBI at each $P_{\mathrm{f}}$ value. The irradiation less than $0.12 \mathrm{MGy}$ and more than $0.65 \mathrm{MGy}$ enhances the $a_{\mathrm{uc}}$ value of the CFRTP at high $P_{\mathrm{f}}$ value of 0.85 . The irradiation less than $0.22 \mathrm{MGy}$ slightly enhances the $a_{\mathrm{uc}}$ value of the CFRTP at mid $P_{\mathrm{f}}$ value of 0.50 .

Although the irradiation doesn't tremendously increase the $a_{\mathrm{uc}}$ value at high $P_{\mathrm{f}}$ value, remarkable effects of HLEBI from 0.12 to $0.86 \mathrm{MGy}$ on $a_{\mathrm{uc}}$ value of CFRTP have been obtained at low $P_{\mathrm{f}}$ value of 0.13 . The irradiation less than 


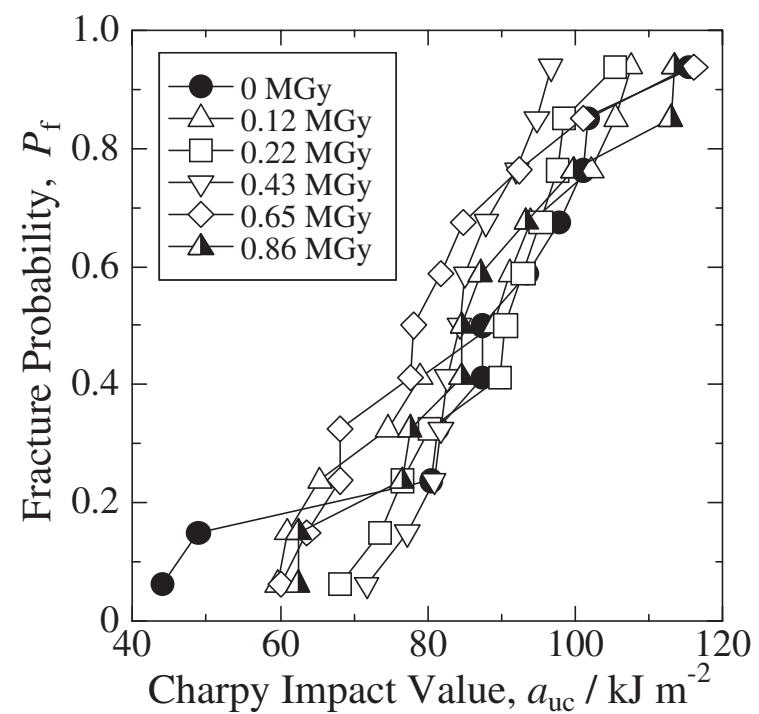

Fig. 2 Relationships between Charpy impact value $\left(a_{\mathrm{uc}}\right)$ of carbon fiber reinforced thermoplastic PEEK $\left(\right.$ CFRTP) and fracture probability $\left(P_{\mathrm{f}}\right)$ at each electron beam irradiation.

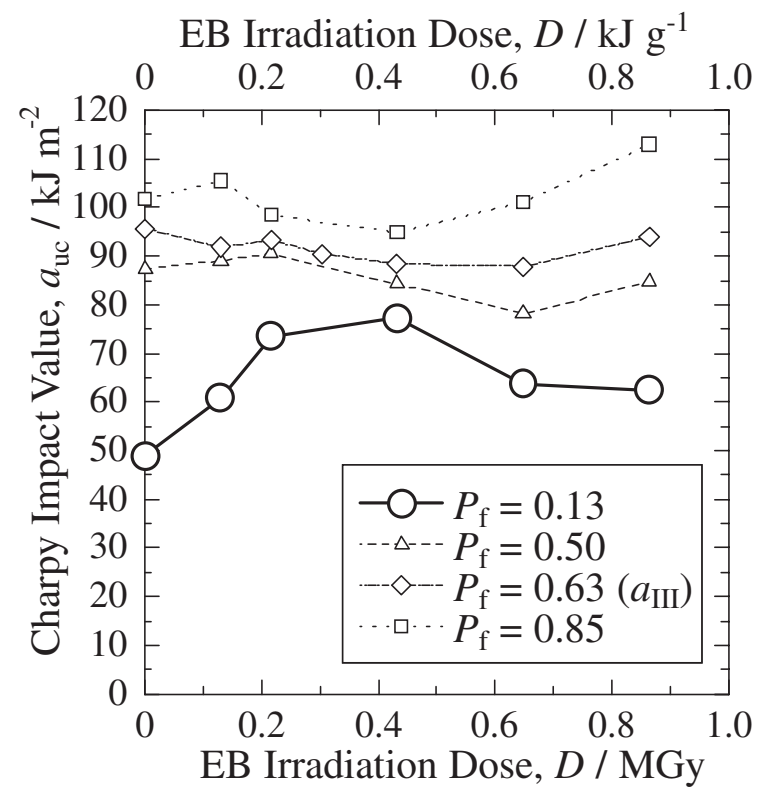

Fig. 3 Changes in experimental impact values $\left(a_{\mathrm{uc}}\right)$ at each fracture probability $\left(P_{\mathrm{f}}=0.13,0.50,0.63\left(a_{\mathrm{III}}\right)\right.$ and 0.85$)$ of carbon fiber reinforced thermoplastic PEEK (CFRTP) plotted against the EB irradiation dose.

0.43 MGy apparently enhances the $a_{\mathrm{uc}}$ value of the CFRTP at low $P_{\mathrm{f}}$ value of 0.13 . 0.43 MGy HLEBI enhances the $a_{\mathrm{uc}}$ value from 50 to $78 \mathrm{kJm}^{-2}$. The $a_{\mathrm{uc}}$ value of CFRTP irradiated at $0.43 \mathrm{MGy}$ is about $60 \%$ higher than that without irradiation at low $P_{\mathrm{f}}$ value of 0.13 .

\subsection{Dangling bond formation}

From the conventional X-ray diffraction patterns of the carbon fiber before and after the EB irradiation, remarkable difference cannot be observed. On the other hand, EB irradiation in fact produces detectable dangling bonds. ${ }^{7-9)}$ To discuss the influences of electron beam irradiation on the Charpy impact values, ESR signals related to dangling bonds have been observed.

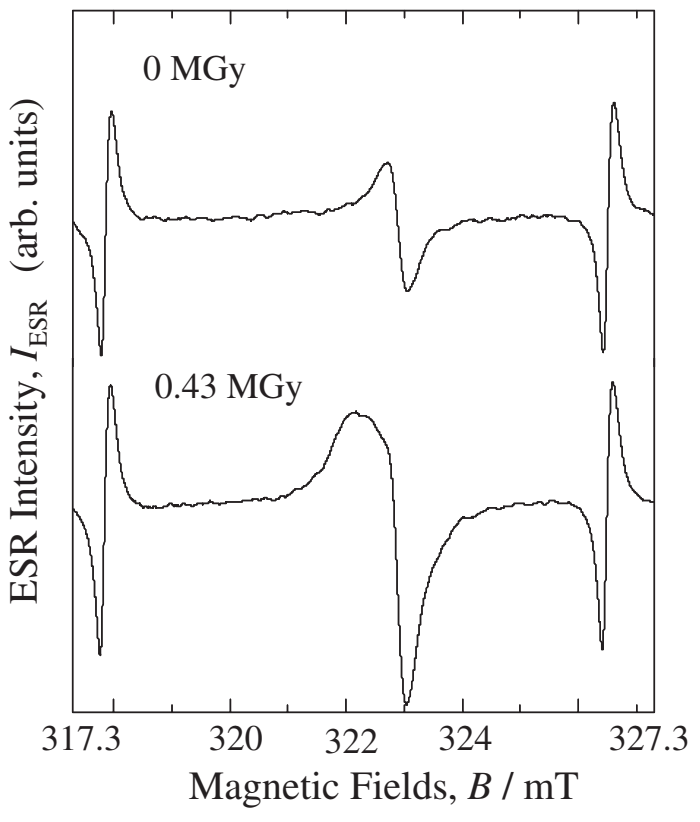

Fig. 4 ESR signals of PEEK before and after EB irradiation.

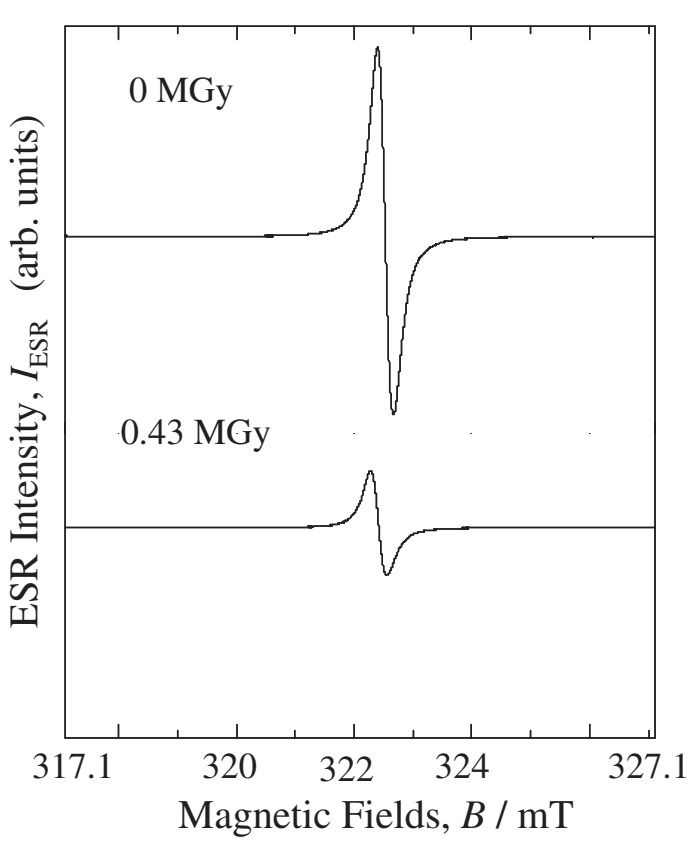

Fig. 5 ESR signals of carbon fibers before and after EB irradiation.

Figure 4 shows the ESR signals at $322.8 \mathrm{mT}$ of PEEK with and without EB irradiation. ESR signals are observed for the PEEK samples before and after irradiation corresponding to dangling bonds (see Fig. 4). As shown in Fig. 4, the electron beam irradiation at $0.43 \mathrm{MGy}$ increases the intensity of ESR signal, which exhibits to generate the dangling bonds in PEEK.

Figure 5 shows the ESR signals at $322.4 \mathrm{mT}$ of carbon fiber with and without EB irradiation. A sharp ESR signal, corresponding to dangling bonds, is detected in the carbon fiber before irradiation (see Fig. 5). EB-irradiation decreases the height of sharp ESR signal of carbon fiber. 


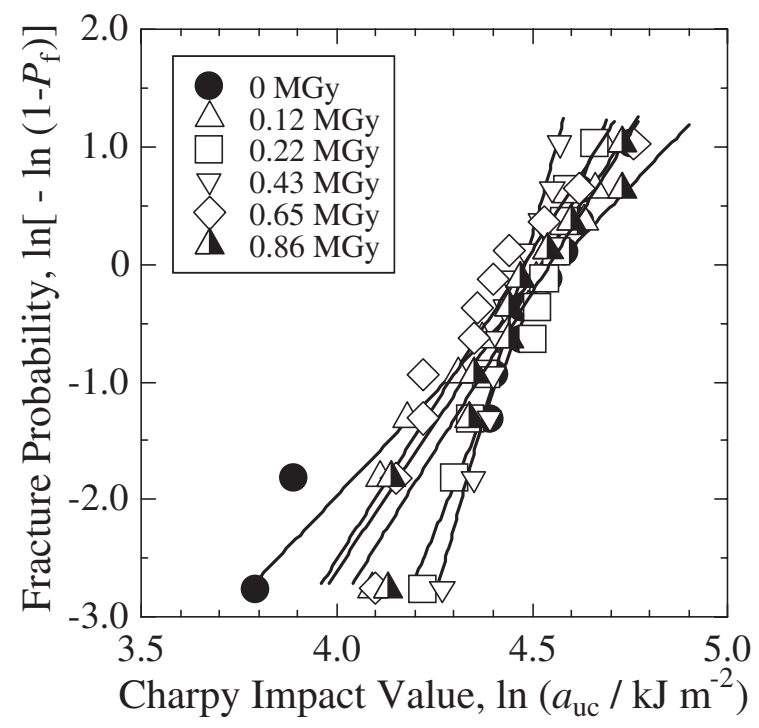

Fig. 6 Weibull plots of CFRTP irradiated by electron beam at each dose.

\section{Discussion}

\subsection{Influence of HLEBI on Weibull coefficient $(n)$ of impact value of CFRTP}

The Weibull coefficient $(n)$ is one of standard and traditional factors to compare with many other structural materials. ${ }^{17)}$ When $a_{\mathrm{uc}}$ and $a_{\mathrm{o}}$ are measured Charpy impact value and constant, $P_{\mathrm{f}}$ as a function of the risk of rupture $\left(a_{\mathrm{uc}} / a_{\mathrm{o}}\right)$ is expressed by the following equation. ${ }^{17)}$

$$
P_{\mathrm{f}}=1-\exp \left[-\left(a_{\mathrm{uc}} / a_{\mathrm{o}}\right)^{n}\right]
$$

The linear relationship can be obtained as the following equation.

$$
\ln \left(-\ln \left(1-P_{\mathrm{f}}\right)\right)=n \ln a_{\mathrm{uc}}-n \ln a_{\mathrm{o}}
$$

Figure 6 shows Weibull plots of CFRTP irradiated by the electron beam at each dose. The $n$ value corresponds to the slopes of the relationships of Weibull plots.

Figure 7 shows the change in $n$ value against EB irradiation dose. The EB irradiation enhances the $n$ value.

The highest $n$ value of CFRTP is obtained at $0.43 \mathrm{MGy}$. EB irradiation from 0.13 to $0.86 \mathrm{MGy}$ apparently enhances the reliability related to $n$ value of impact value of CFRTP.

As a results, HLEBI enhances the reproducibility with decreasing the experimental errors.

\subsection{Effects of HLEBI on the lowest impact value}

On the other hand, since the experimental impact values at less than 0.2 of low $P_{\mathrm{f}}$ value have been largely deviated from the linear relationship (see Fig. 6), the practical impact value at low $P_{\mathrm{f}}$ value cannot be estimated.

If the statistic equation is assumed to be applicable to the measured $a_{\mathrm{uc}}$ value, the $P_{\mathrm{f}}$ value depends on the risk of rupture $\left(\left[a_{\mathrm{uc}}-a_{\mathrm{s}}\right] / a_{\mathrm{III}}\right){ }^{18,19)}$

$$
P_{\mathrm{f}}=1-\exp \left[-\left(\left[a_{\mathrm{uc}}-a_{\mathrm{s}}\right] / a_{\mathrm{III}}\right)^{m}\right]
$$

In predicting the required impact value of the new structural materials, the lowest impact value $\left(a_{\mathrm{s}}\right)$, the coefficient $(m)$ and constant $\left(a_{\mathrm{III}}\right)$ are key parameters. The

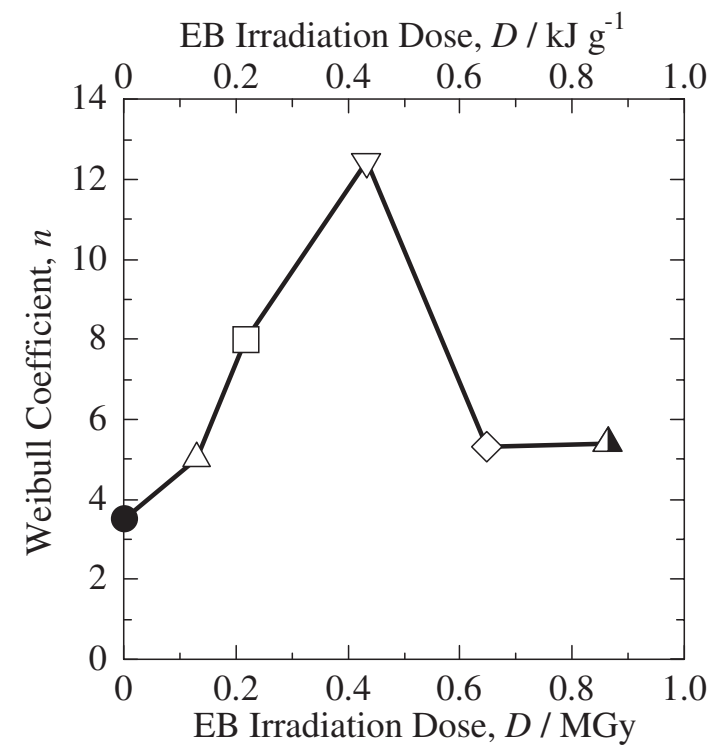

Fig. 7 Changes in Weibull coefficient (n) of CFRTP against the EB irradiation dose.

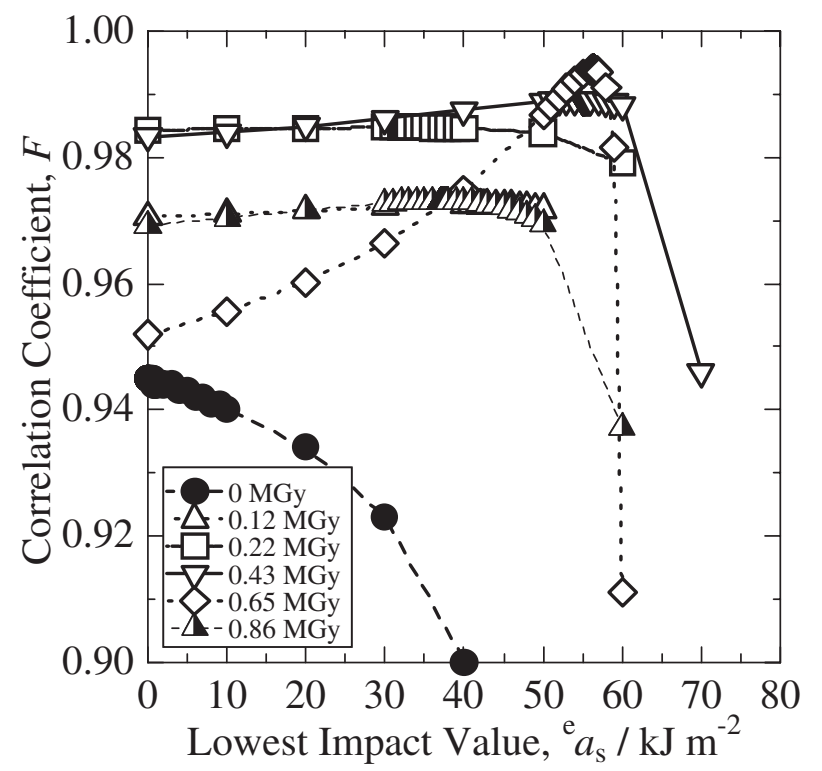

Fig. 8 Changes in correlation coefficient $(F)$ of eq. (7) against the potential $a_{\mathrm{s}}$ value $\left({ }^{\mathrm{e}} a_{\mathrm{s}}\right)$. The lowest impact value $\left(a_{\mathrm{s}}\right)$ was determined at the maximum $F$ value.

$a_{\mathrm{III}}$ is the $a_{\mathrm{uc}}$ value at 0.632 of $P_{\mathrm{f}}$, when the term $\left(\ln \left[-\ln \left(1-P_{\mathrm{f}}\right)\right]\right)$ is zero. A change in the $a_{\mathrm{III}}$ value with respect to EB irradiation dose is also shown in Fig. 3. The $a_{\text {III }}$ values of EB irradiated CFRTP are slightly less than that before treatment.

As the $P_{\mathrm{f}}$ value is equal to zero, the $a_{\mathrm{uc}}$ value is defined as the $a_{\mathrm{s}}$ value. When a correlation coefficient $(F)$ of eq. (7) shows the maximum value, the potential $\left({ }^{\mathrm{e}} a_{\mathrm{s}}\right)$ value can be determined to be as the lowest impact value $\left(a_{\mathrm{s}}\right)$ applied. Figure 8 shows changes in the $F$ value with respect to the ${ }^{\mathrm{e}} a_{\mathrm{s}}$ value. Since the $F$ value is from 0.94 to 0.99 in Fig. 8, the relationships in Fig. 9 exhibit the high linearity.

Figure 10 shows variations of the $a_{\mathrm{s}}$ value against EB irradiation dose, together with the experimental $a_{\mathrm{uc}}$ value at 


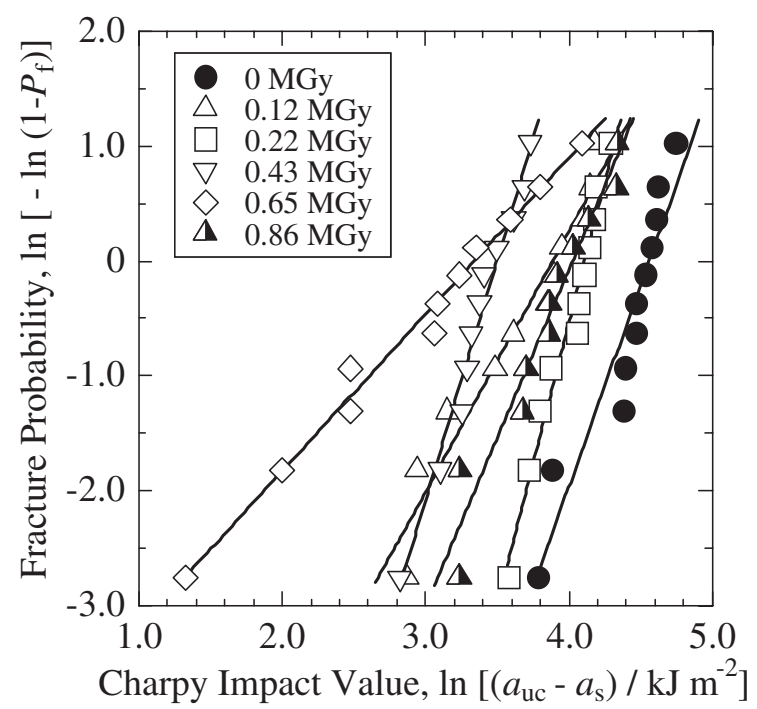

Fig. 9 Linear relationships between $\ln \left(a_{\mathrm{uc}}-a_{\mathrm{s}}\right)$ and $\ln \left[-\ln \left(1-P_{\mathrm{f}}\right)\right]$ for CFRTP irradiated by electron beam at each dosage.

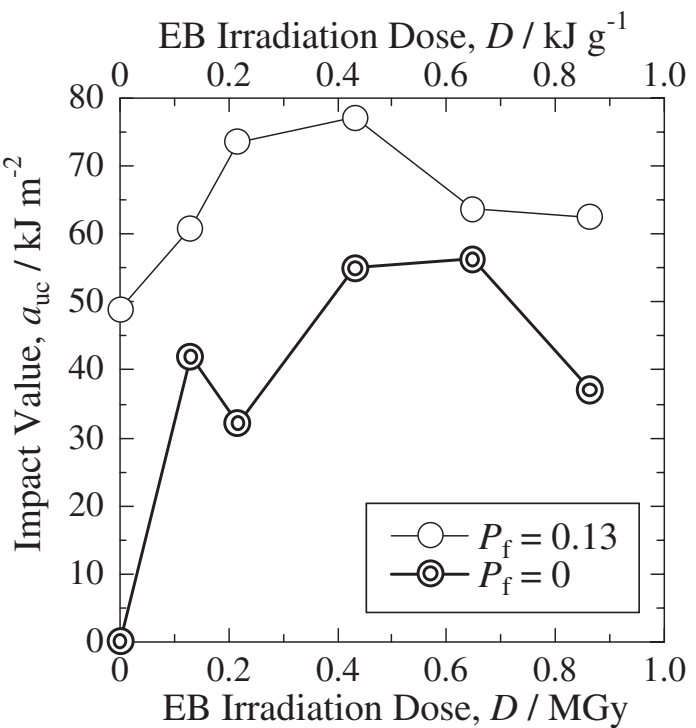

Fig. 10 Changes in experimental impact values $\left(a_{\mathrm{uc}}\right)$ at low $P_{\mathrm{f}}$ of $0.13(\bigcirc)$ and the lowest impact values (○: $a_{\mathrm{s}}=a_{\mathrm{uc}}$ at $P_{\mathrm{f}}=0$ ) plotted against the EB irradiation dose.

the low $P_{\mathrm{f}}$ value of 0.13 for each sample. Since the $a_{\mathrm{s}}$ is the $a_{\mathrm{uc}}$ value at the lowest $P_{\mathrm{f}}$ value of 0 , it is always lower than the experimental $a_{\mathrm{uc}}$ value at low $P_{\mathrm{f}}$ value of 0.13 . Although the $a_{\mathrm{s}}$ value is zero for CFRTP before irradiation, HLEBI enhances the $a_{\mathrm{s}}$ value. HLEBI from 0.13 to $0.86 \mathrm{MGy}$, which exhibits the high $a_{\mathrm{s}}$ value of more than $30 \mathrm{kJm}^{-2}$, enhances the $a_{\mathrm{s}}$ value. Furthermore, the highest $a_{\mathrm{s}}$ value is more than $55 \mathrm{kJm}^{-2}$ for CFRTP irradiated from 0.43 to $0.65 \mathrm{MGy}$.

\subsection{Effects of dangling bonds induced by HIEBL on impact value improvement of CFRTP constructed with carbon fiber, PEEK and their interface}

Improvement of the impact value of CFRTP by HLEBI probably depends on strengthening carbon fiber, ductility enhancement of polymer matrix and enhancement of interfacial friction.
Based on the ESR signals of carbon fiber in Fig. 5, dangling bonds have been observed in carbon fiber before treatment. Based on the standard calibration material TEMPOL (2,2,6,6-tetramethyl-4-piperidinol-1-oxyl) and $\mathrm{Mn}^{2+}$ in the $\mathrm{MnO}$, the density of dangling bonds is estimated by the double integrated intensity of ESR signal. ${ }^{7-9)}$

Dangling bonds generally exist in carbon fiber before irradiation. Based on the ESR signals in Fig. 5, the densities of dangling bonds of carbon fibers before and after 0.43

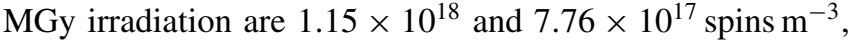
respectively. Dangling bonds generally exist in carbon fiber before irradiation. HLEBI often decreases the density of dangling bonds. Annihilation of dangling bonds has often enhanced the tensile fracture stress and fracture strain of bending tests. ${ }^{7-9)}$

HLEBI annihilates dangling bonds in the hexagonal atomic structure of graphite, ${ }^{8,9)}$ it probably prevents the generation of cracks and often enhances the elasticity, resulting in ductility enhancement and strengthening of the carbon fiber. ${ }^{8,9)}$

In addition, HLEBI often enhances the ductility and strengthening of the polymer matrix. ${ }^{10)}$ Based on the ESR signals of PEEK in Fig. 4, dangling bonds have been also observed in PEEK before treatment. Based on the ESR signals in Fig. 4, the densities of dangling bonds of PEEK samples before and after $0.43 \mathrm{MGy}$ irradiation are $1.23 \times$ $10^{13}$ and $3.81 \times 10^{13}$ spins $\mathrm{m}^{-3}$, respectively. HLEBI increases the density of dangling bonds (see Fig. 4). When HIEBL cuts the weak chemical bonds of PEEK, the repulsive force between terminated atoms with dangling bonds occurs, resulting in generating volume expansion at dangling bonds. The expansion induced by HIEBL generates the compressive stress in PEEK matrix, which prevents to generate and propagate the crack in PEEK matrix.

When the compressive stress induced by HIEBL also enhances the friction force at interface between carbon fiber and PEEK, it prevents to pull out the carbon fiber from the PEEK matrix.

Based on both effects of compressive stress, HIEBL enhances the impact values of CFRTP. The interfacial friction force, as well as the strengthening of both carbon fiber and polyetheretherketone probably contributes the HLEBI effects to enhance the $a_{\mathrm{s}}$ value of CFRTP, as well as reproductively enhancement with decreasing the experimental errors.

On the other hand, additional EB irradiation of more than $0.86 \mathrm{MGy}$ apparently decreases the impact value at low $P_{\mathrm{f}}$ value, as shown in Figs. 2 and 3. Since the additional irradiation easily breaks the chemical bonds of PEEK polymer and carbon fiber, it probably not only generates many crack origins, but also links cracks with crack propagation. The decay of impact values of CFRTP irradiated at $0.86 \mathrm{MGy}$ can be explained by the excess formation of dangling bonds.

\subsection{Penetration depth of electron supplied from HLEBI system in CFRTP}

Penetration depth of electron beam is one of serious problem to dominate the productivity and CFRTP thickness to apply the practical use. Based on the density $\left(\rho: \mathrm{kgm}^{-3}\right)$ 


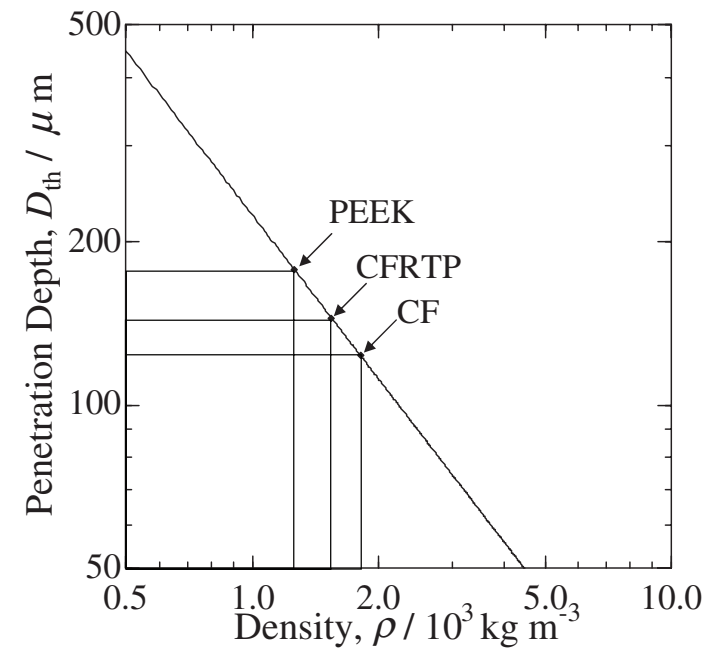

Fig. 11 Change in penetration depth against sample density.

and irradiation voltage $(V: \mathrm{kV})$, the EB-irradiation depth $\left(D_{\mathrm{th}}: \mathrm{m}\right)$ is expressed by the following equation. $\left.{ }^{15}\right)$

$$
\begin{aligned}
& D_{\text {th }}=66.7 V^{5 / 3} / \rho \\
& \log D_{\text {th }}=\log 66.7+5 / 3 \log V-\log \rho
\end{aligned}
$$

The surface electrical potential $(128 \mathrm{keV})$ is estimated from the electrical potential $(170 \mathrm{keV})$, the $10 \mu \mathrm{m}$ thickness of the titanium (density: $4540 \mathrm{kgm}^{-3}$ ) window and the $30 \mathrm{~mm}$ distance between the sample and the window in the nitrogen gas atmosphere (density: $1.13 \mathrm{kgm}^{-3}$ ). Since the measured density of the CFRTP sample is $1546 \mathrm{kgm}^{-3}\left(1.546 \mathrm{kgL}^{-1}\right)$, the EB-irradiation depth estimated from eq. (9) is $1.45 \times$ $10^{-4} \mathrm{~m}(145 \mu \mathrm{m})$. Figure 11 shows density dependent effective depth of EB-irradiation for carbon fiber $\left(1810 \mathrm{kgm}^{-3}\right)$, PEEK $\left(1260 \mathrm{kgm}^{-3}\right)$ and CFRTP, in which the volume fraction of carbon fiber in PEEK is $52.6 \mathrm{vol} \%$. By using the relation and density, effective depth of EB-irradiation for carbon fiber, PEEK and CFRTP are 123, 177 and $145 \mu \mathrm{m}$. Since the effective depth of the sheet electron beam irradiation is $0.29 \mathrm{~mm}$ in the CFRTP, the irradiated depth from each sample surface is $14.5 \%$ of the CFRTP sample thickness of $2.0 \mathrm{~mm}$.

On the other hand, the HLEBI depth $\left(D_{\mathrm{th}}: \mathrm{m}\right)$, related to the mass thickness $\left(l_{0}: \mathrm{gm}^{-2}\right)$ and irradiation voltage $(E: \mathrm{kV})$, is also expressed by the following equation suggested by Libby. ${ }^{20)}$

$$
l_{0}=E^{5 / 3} / 15
$$

The estimated mass thickness is $348 \mathrm{gm}^{-2}$, when initial irradiation voltage is $170 \mathrm{keV}$. Since the mass thickness values of Ti foil $\left(17.8 \mathrm{gm}^{-2}\right)$ and $\mathrm{N}_{2}$ gas $\left(1.50 \mathrm{gm}^{-2}\right)$ reduce the EB-irradiation depth, the mass thickness of CFRTP sample is $323 \mathrm{gm}^{-2}$. In addition, the irradiation voltage on sample surface is expressed by the following equation.

$$
E=\left(15 l_{0}\right)^{3 / 5}
$$

Namely, the EB-irradiation depth of CFRTP is obtained by assumptions of Christenhusz and Reimer (see eq. (9)), ${ }^{15)}$ and Libby. ${ }^{20)}$ Effective depth of EB-irradiation for carbon fiber, PEEK and CFRTP are 123, 177 and $145 \mu \mathrm{m}$ by using the

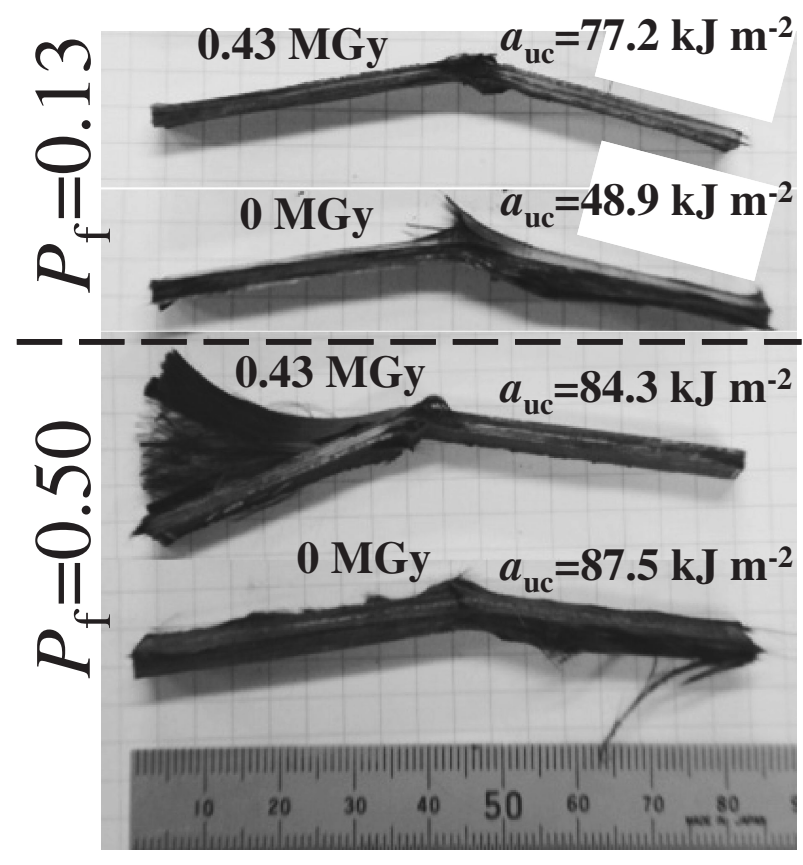

Fig. 12 Photograph of fractured CFRTP before and after irradiation.

assumption of Christenhusz and Reimer (see eq. (9)), and are 178,257 and $209 \mu \mathrm{m}$ by using the assumption of and Libby. ${ }^{20)}$

Although the irradiated depth estimated is $177 \pm 32 \mu \mathrm{m}$ at both sides surface of composite sheet with $2 \mathrm{~mm}$ thickness, we concludes that the HLEBI improves the impact value of CFRTP.

Based on the results of impact fracture of CFRP at each $P_{\mathrm{f}}$ value, ${ }^{11)}$ the interfacial fracture between fiber and matrix as well as bending fracture at the impact point occurs at high $P_{\mathrm{f}}$ value, whereas the bending fracture mainly occurs at low $P_{\mathrm{f}}$ value. Figure 12 shows photographs of fractured CFRTP samples before and after irradiation. Although the interfacial fracture with fiber pull-out as well as bending fracture apparently occurs of the fractured fuzzy CFRTP samples at high $P_{\mathrm{f}}$ value of 0.5 , the simple bending fracture mainly occurs of irradiated CFRTP with the highest $a_{\mathrm{uc}}$ value at low $P_{\mathrm{f}}$ values of 0.13 . Since HLEBI prevents to fracture at the interface and enhances the $a_{\mathrm{uc}}$ value at low $P_{\mathrm{f}}$ value, we conclude that HLEBI probably enhances the resistance to interfacial fracture as well as impact bending fracture of the CFRTP.

The impact fracture generally occurs near the surface. When the interfacial fracture occurs at the high $P_{\mathrm{f}}$ value (see Fig. 12), the fiber peeling and fiber pull-out are mostly observed at the fuzzy surface zone from surface to $300 \mu \mathrm{m}$ depth. Since it is larger than that of the penetration depth of irradiation, the surface zone treated by HLEBI probably enhances the resistance to interfacial fracture as well as impact bending fracture of CFRTP, resulting in improvement of the $a_{\mathrm{uc}}$ value at low $P_{\mathrm{f}}$ value.

On the other hand, HLEBI doesn't improve the $a_{\mathrm{uc}}$ value at high $P_{\mathrm{f}}$ value within experimental errors, because the interfacial adhesive force of CFRTP before irradiation is large enough. Therefore, HLEBI improves the $a_{\mathrm{uc}}$ value at low $P_{\mathrm{f}}$ value of CFRTP sample. 


\section{Conclusion}

In summary, effects of homogeneous low voltage electron beam irradiation (HLEBI) on impact value of carbon fiber reinforced thermoplastic polyetheretherketone (CFRTP) have been found, although the irradiated depth estimated is $177 \pm 32 \mu \mathrm{m}$ at both sides surface of composite sheet with $2 \mathrm{~mm}$ thickness.

(1) The experimental impact value $\left(a_{\mathrm{uc}}\right)$ at low fracture probability $\left(P_{\mathrm{f}}\right)$ of 0.13 for CFRTP irradiated at $0.43 \mathrm{MGy}$ $\left(\mathrm{kJg}^{-1}\right)$ is $78 \mathrm{kJm}^{-2}$, which is $56 \%$ higher than that $\left(50 \mathrm{kJm}^{-2}\right)$ for CFRTP before irradiation. Thus, the HLEBI enhances the fracture toughness related to impact values at low $P_{\mathrm{f}}$ value.

(2) Although the $a_{\mathrm{s}}$ value is zero for CFRTP before irradiation, HLEBI enhances the $a_{\mathrm{s}}$ value. HLEBI from 0.13 to $0.86 \mathrm{MGy}$, which exhibits the high $a_{\mathrm{s}}$ value of more than $30 \mathrm{kJm}^{-2}$, enhances the $a_{\mathrm{s}}$ value. Furthermore, the highest $a_{\mathrm{s}}$ value is more than $55 \mathrm{kJm}^{-2}$ for CFRTP irradiated from 0.43 to $0.65 \mathrm{MGy}$.

(3) Since HLEBI enhances the Weibull coefficient $(n)$, it also enhances the reproductively of CFRTP samples, as well as increasing the $a_{\mathrm{s}}$ value. The maximum $n$ value is found at 0.43 MGy of HLEBI dose.

(4) The interfacial friction force, as well as the strengthening of both carbon fiber and polyetheretherketone, probably contributes the HLEBI effects to enhance the $a_{\text {s }}$ value of CFRTP, as well as reproductively enhancement with decreasing the experimental errors.

\section{Acknowledgement}

Authors would like to thank Prof. Dr. Akira Tonegawa, Dr. Tadae Morishita and Hironori Satoh, Masae Kanda, Ryuichi Suenaga, Noriyoshi Miwa and Naoto Hironaka of Tokai University for their useful helps. This work is partly supported by Minister of Industry and ENSM-SE in France.

\section{REFERENCES}

1) D. K. Thomas: Plastics Rubber Int. 8 (1983) 53-57.

2) M. B. Dowell: Plastics Eng. 33 (1977) 31-32.

3) K. Sonoda, Y. Kaneda, I. K. Nakazaki, Z. Enomoto and K. Murayama: Proc. Symp. Space sciences and technology (Utyu kagaku gizyutu renngou kouennkai kouennsyu, JST No. S0277A) 28 (1984) pp. 14-15.

4) K. Oguri, N. Iwataka, A. Tonegawa, Y. Hirose, K. Takayama and Y. Nishi: J. Mater. Res. 16 (2001) 553-557.

5) K. Oguri, K. Fujita, M. Takahashi, Y. Omori, A. Tonegawa, N. Honda, M. Ochi, K. Takayama and Y. Nishi: J. Mater. Res. 13 (1998) 33683371.

6) K. Oguri, N. Iwatani, H. Izumi, A. Tonegawa, K. Takayama and Y. Nishi: Proc. 2nd Japan-France Seminar on Intelligent Materials and Structures, (University of Louis Pasteur Strasbourg, France, 1998) pp. 142-144.

7) Y. Nishi, A. Mizutani and N. Uchida: J. Thermoplast. Compos. Mater. (ISSN 0892-7057) 17 (2004) 289-302.

8) Y. Nishi, T. Toriyama, K. Oguri, A. Tonegawa and K. Takayama: J. Mater. Res. 16 (2001) 1632-1635.

9) Y. Nishi, A. Mizutani, A. Kimura, T. Toriyama, K. Oguri and A. Tonegawa: J. Mater. Sci. 38 (2003) 89-92.

10) A. Mizutani and Y. Nishi: Mater. Trans. 44 (2003) 1857-1860.

11) Y. Nishi, K. Inoue and M. Salvia: Mater. Trans. 47 (2006) 2846-2851.

12) H. Sato, K. Iwata, A. Tonegawa and Y. Nishi: J. Jpn. Inst. Metals 72 (2008) 526-531.

13) M. Makihara: Plastics (ISSN 0555-7887) 53 (2002) 119-122.

14) Japanese Industrial Standards Committee: JIS K7077 (1991).

15) R. Christenhusz and L. Reimer: Z. Angew. Phys. 23 (1967) 396-404.

16) T. Nishida and E. Yasuda: Evaluation of dynamic properties of ceramics (in Japanese: Ceramics no rikigaku tokusei hyouka) (Nikkan Kogyou Shimbun Sha, Tokyo, 1986) pp. 50-51.

17) W. Weibull: Ingeniörs vetenskaps akademien, nr. 151 (Generalstabens litografiska anstalts förlag, Stockholm, 1939) pp. 12-14.

18) Y. Nishi, H. Kobayashi and M. Salvia: Mater. Trans. 48 (2007) 19241927.

19) W. Weibull: Ingeniörs vetenskaps akademien, nr. 153 (Generalstabens litografiska anstalts förlag, Stockholm, 1939) pp. 16-22.

20) W. F. Libby: Anal. Chem. 19 (1947) 2-6. 